ISSN: $1231-4005$

e-ISSN: $2354-0133$

ICID: 1133865

DOI: $10.5604 / 12314005.1133865$

\title{
THE INFLUENCE OF RME ON MASS AND NUMBER CONCENTRATION OF NANO PM IN EXHAUST GASES FROM A DIESEL ENGINE
}

\author{
Jerzy Cisek \\ Cracow University of Technology \\ Institute of Automobiles and Internal Combustion Engines \\ Jana Pawla Av. II 37, 31-864 Krakow, Poland \\ e-mail: jcisek@pk.edu.pl
}

\begin{abstract}
Transport is a major source of the particle pollution (PM). Combustion engine particulate emissions have the potential cause adverse health effects. These effects include cancer and other pulmonary and cardiovascular diseases. A substantial proportion of the number of particles, but not the mass, is ultrafine. For example - one million particles of 100 nanometers size with a unit density of $1 \mathrm{~g} / \mathrm{cm} 3$ have a mass of approximately $0.0005 \mathrm{~g}$. The paper includes research results of mass and number concentration of nanoPM for 1.9 TDI VW exhaust gases fuelled by standard diesel. The measurements were performed for ambient air and 3 different point of engine work (idle speed, low and high load at $2000 \mathrm{rpm}$ ). For nanoPM measurements was used Electrical Low Pressure Impactor ELPI from DECATI, was found, among other things, that the biggest mass concentration was at 0.1-10 um of PM diameter but the biggest number concentration was at 0,01-0,1 $\mu m$ and thus for the size of solid particles of at least an order of magnitude smaller than the mass concentration. The biggest the negative differences in the mass concentration occur in the exhaust gases of the RME fuelled engine (in comparison with diesel fuel) at engine idling when the smallest injection pressure and temperature inside the engine cylinder exist and the oxygen availability is also the lowest (because of the small charging pressure and high EGR rate). Such measurements are important not only in terms of utilitarian but also in cognitive sense - for determining the effect of the engine construction parameters and/or regulating the engine (or the fuel composition) on the mass and the number of nanoparticles emitted in the exhaust gases.
\end{abstract}

Keywords: Nanoparticles, mass and number concentration, FAME, RME, Diesel Engine.

\section{Introduction}

Over the last dozen years, there has been a sudden increase in concern about the issue of the emission of nanoparticles and ultra-fine particles. This has resulted in new standards introduced by the United States Environmental Protection Agency - EPA for fine particles in the atmosphere and acceptable levels of annual average concentration, determined by the $E P A$ as $50 \mu \mathrm{g} / \mathrm{m}^{3}$ for PM10 (particles of aerodynamic diameter up to $10 \mu \mathrm{m}$ ). In addition, the updating of these standards includes an extension of the concentration limitation with a concentration level of $15 \mu \mathrm{g} / \mathrm{m}^{3}$ for PM2.5 (particles of aerodynamic diameter up to $2.5 \mu \mathrm{m}$ ). In large measure, the new EPA standards are based on scientific research, which demonstrates a strong correlation between human and animal mortality and the mass of fine particles below $2.5 \mu \mathrm{m}$. A range of studies has inspired anxiety about even smaller particles - ultra-fine particles and nanoparticles, which are defined as particles with diameters below $100 \mathrm{~nm}$ and $50 \mathrm{~nm}$ respectively. Inter alia, strong reactions from respiratory systems and $D N A$ chain damage caused by nanoparticles have been found. Such anxieties increased in consequence of observations that modern combustion engines emitting lowmass concentrations of particles (determined in accordance with valid gravimetric methods) can actually emit quantitative concentrations of particles higher than older engines. It has also been demonstrated that a substantial part of the mass production filters of particulates (whose use is forced by the need to reduce the mass emission of particles) induces generation of very high concentrations of nanoparticles. 


\section{Particulates (PM)}

According to the definition provided by the ISO and ECE standards [1, 2], particulates emitted by combustion engines cover all semi-fluid and fluid matter, either organic or inorganic, which accumulates on an absolute filter after a stream of air-diluted exhaust gases is passed through it at a temperature equal to or lower than $52^{\circ} \mathrm{C}$, under the conditions laid down by these standards. The particulates, which constitute a poly-dispersive system, are generated as a result of the complex chemical and physical reactions frequently occurring simultaneously at different spaces and times. Therefore, a portion of hydrocarbon gaseous fraction may increase PM emission (at the cost of decreased $\mathrm{HC}$ emission) after being condensed. As particulates (PM) (PM-Particulate Matter) emitted by combustion engines, the commonly accepted substance are products (solid or fluid) leaving the engine exhaust system, which contain among other things a certain quantity of carbon particles (carbon black), sulphur and nitrogen compounds, metals and heavy hydrocarbons. Fig. 1 gives an example scheme of Particulate Matter (PM) [3], while Fig. 2 shows a photograph of a solid particle on a measuring filter.

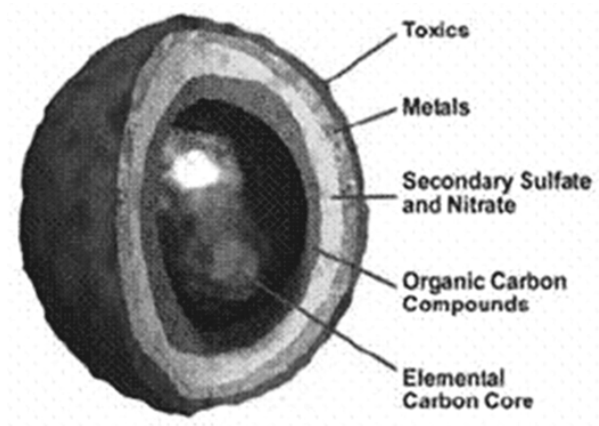

Fig. 1. Structural scheme of Particulate Matter (PM) [3]

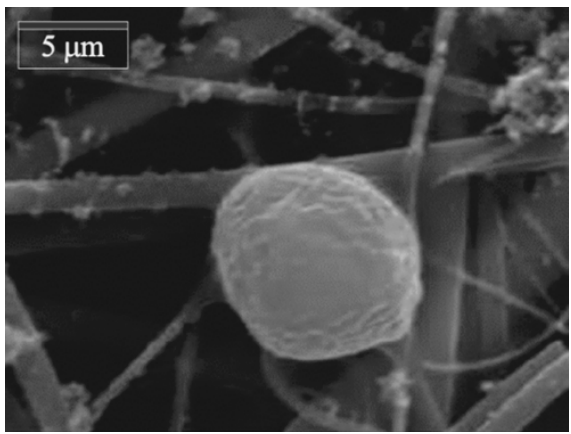

Fig. 2. Photograph of PM on a filter [5]

As mentioned above, the mass concentration and number concentration of particulates are not identical. An example of PM mass-concentration and number concentration in engine exhaust gases as a function of PM diameter is shown in Fig. 3. It may occur that some construction and/or regulation and/or fuel and/or post-process changes may cause a reduction in the PM mass emission with a simultaneous increase in the number concentration (quantity) of particulates. For this reason, this study presents both the mass concentration and number concentration of nanoparticles as determined in the exhaust gases of the engine used for measuring.

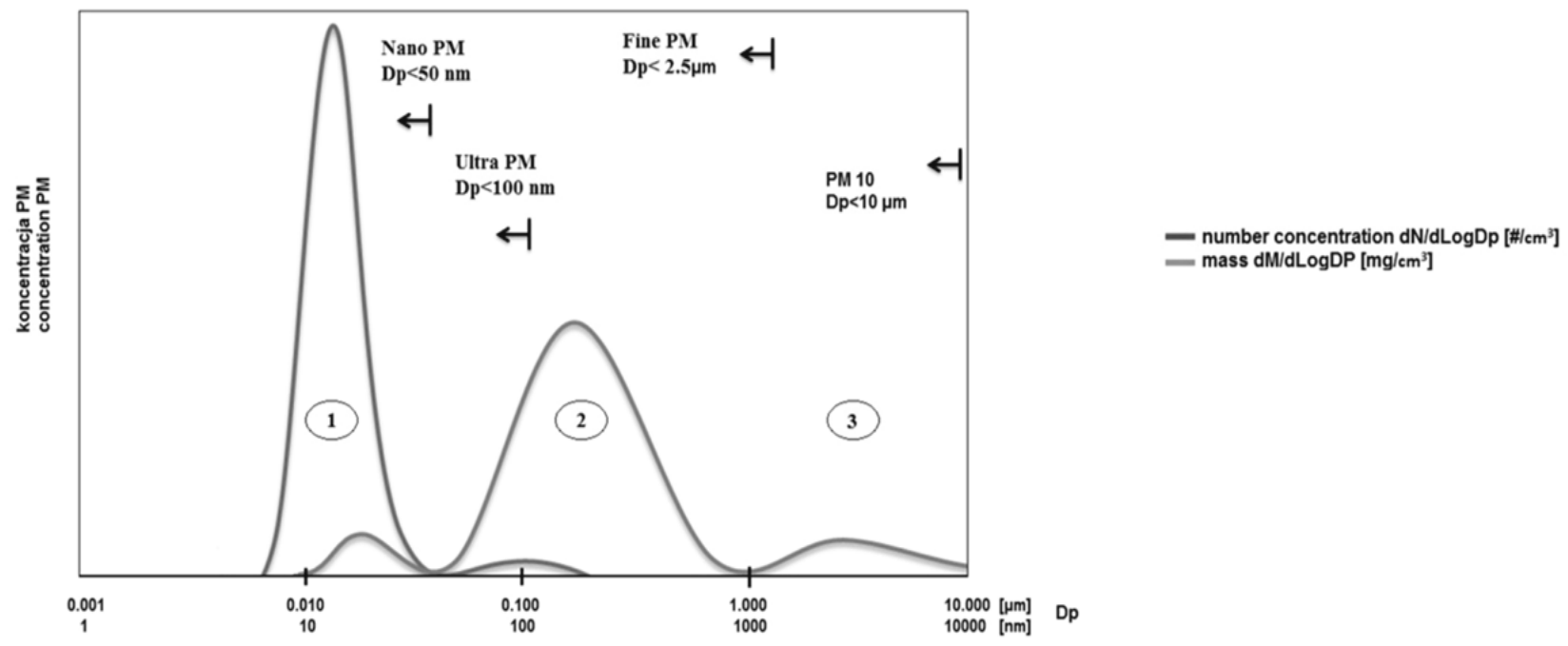

Fig. 3. PM number concentration and mass concentration as a function of substitute diameters [3] 


\section{Scope of Research and Test Bed}

In this paper, the measuring results and analyses of the distribution of mass and number concentration of particulates in exhaust gases distribution are published as a function of their sizes (substitute diameters) for different loads of a 1.9TDI VW engine. For measurements, a DECATI Electrical Low Pressure Impactor (ELPI) was used. The ELPI enables the concentration of "particulate matter" to be measured within a range of $6 \mathrm{~nm}$ and $10 \mu \mathrm{m}$, with separation of the mass and quantity of particles split into 14 fractions depending on their diameters. The ELPI may also be used for collecting the particulate matter in individual decades for further analysis (e.g. chemical analyses). The scheme of measurement with the ELPI is demonstrated in Fig. 4 [2].

In the study, we used a 1.9TDI VW turbo-charging engine equipped with injection units (285 $\mathrm{Nm}, 85 \mathrm{~kW}$, type AJM). This engine was connected to a Schenck W150 (12) eddy-current engine brake and the necessary measuring apparatus including an AVL dynamic mass meter of fuel consumption (11), AVL Indimeter 617D (37), AVL VideoScope 513D, an AVL CEB II (19) measuring system for measuring the concentration of the gaseous components of exhaust gases, an AVL Smoke Meter 401 (11), the test bed with a diluting tunnel for gravimetric measurements of PM emission (28) and the DECATI Electrical Low Pressure Impactor ELPI (30), for measuring the mass and number concentration of particulates in the engine exhaust gases. The measurements were taken with the engine in a factory configuration and fuelled by a standard commercial diesel fuel. The test bed scheme is presented in Fig. 5.

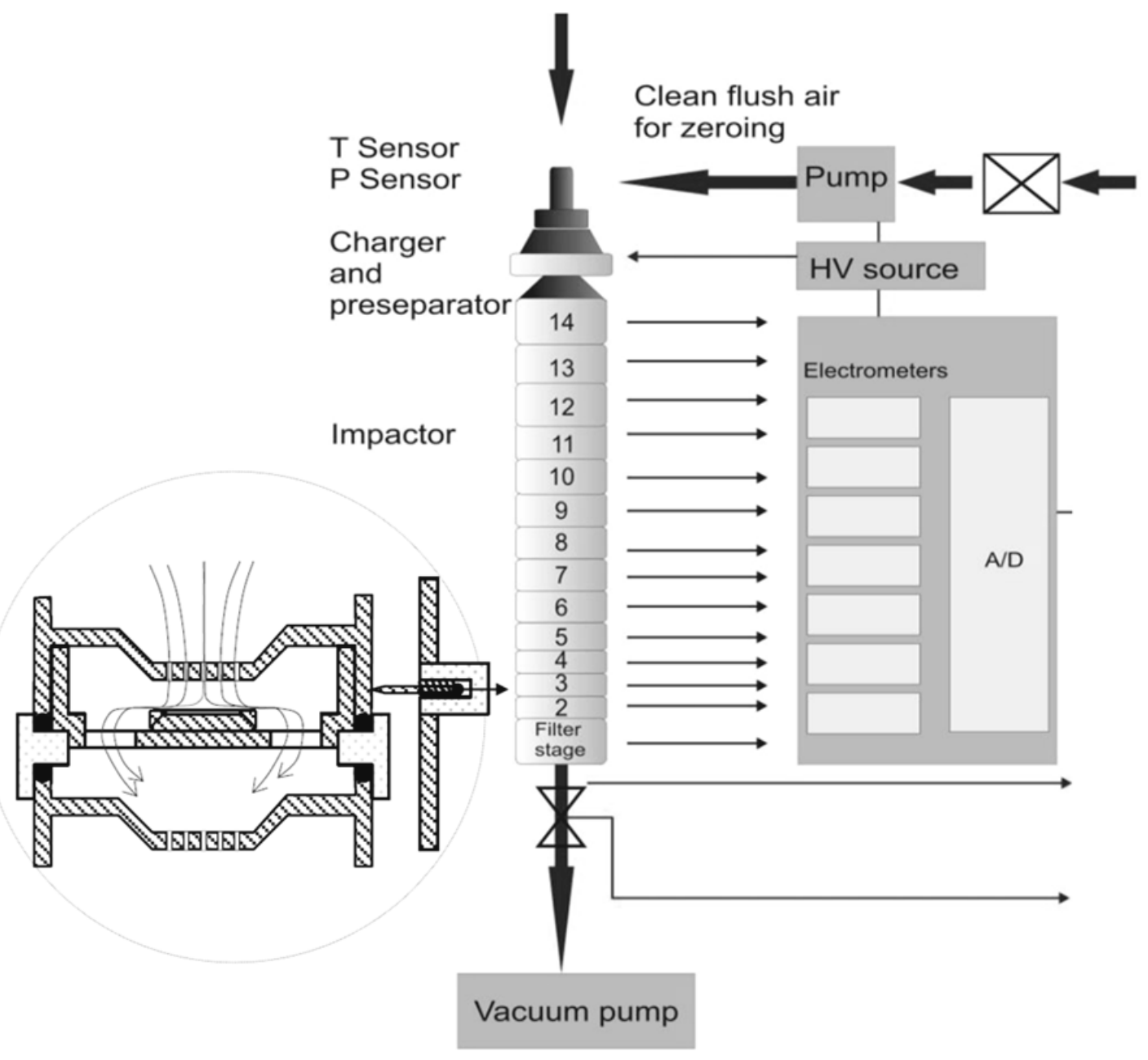

Fig. 4. ELPI Functional Diagram [4] 


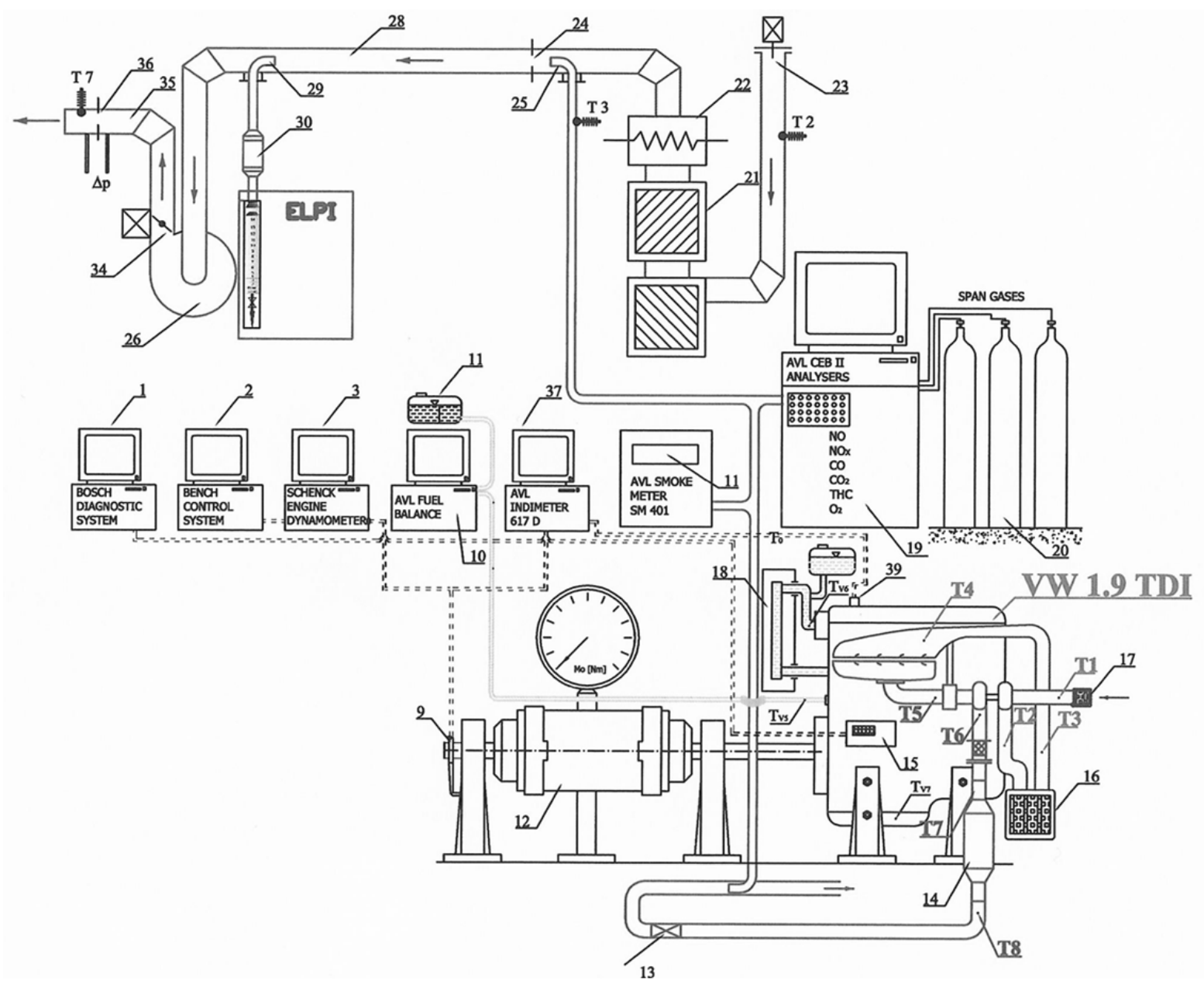

Fig. 5. Test Bed Scheme (described above)

\section{Analyses and Findings}

All measurements were taken for ambient air and exhaust gases of the engine running at 2000 rpm for idle running and then for $75 \mathrm{Nm}$ and $200 \mathrm{Nm}$ load (i.e., "low" and "high" load for this type of engine). For all working points, the engine was fuelled by a standard diesel fuel or RME (FAME). The research results (obviously taking into account the dilution degree of exhaust gases) are shown in Fig. 6 and 7.

In this study, among other things, we ascertained that for a given fuel the engine load obviously has a strong influence on the number concentration and mass concentration of particles; nevertheless, it does not significantly change the distribution of these concentrations considered as a function of particle substitute diameters. The highest mass concentration of particles was observed for particles from a range between 0.1 and $10 \mu \mathrm{m}$ and thus for relatively big particles. As the engine load increased, the maximum mass concentration of particulates occurred for increasingly bigger particle sizes. Nevertheless, the biggest quantity (number) of particles in the exhaust gases occurred for particle sizes between 0.01 and $0.1 \mu \mathrm{m}$.

There is inherently a strong influence from the type of fuel (diesel fuel/RME) on the number and mass concentration of nano-PM in the engine exhaust gases, but this also depends on the engine loads. For idle running ( $830 \mathrm{rpm}, \mathrm{M}=0 \mathrm{Nm}$ ) in the exhaust gases of the engine fuelled by RME, the measured PM mass concentration $\left(80 \mathrm{mg} / \mathrm{m}^{3}\right)$ was significantly higher than for the diesel fuel $\left(2.5 \mathrm{mg} / \mathrm{m}^{3}\right)$ and there were significantly larger particles $(10 \mu \mathrm{m})$ than for a standard fuel (approx. $0.1 \mu \mathrm{m}$ ). This is possibly a consequence of the fact that under such engine working conditions a low pressure of fuel injection occurred as well as low combustion temperature. In 
addition, the EGR (Exhaust Gas Recirculation) rate is very high, about 70\%, which reduces the volume of clean air available for combustion. These conditions are extremely unfavourable for the oxidation of Rapeseed Methyl Esters (RME). At the same time, however, the number concentration of nanoparticles is lower for the bio-fuel than for diesel oil. Possibly, in the case of RME, small particles created big conglomerates (visible in the mass concentration) and therefore they were almost half the number than in the case of a standard hydrocarbon fuel.

For a low engine load $(2000 \mathrm{rpm}, 75 \mathrm{Nm})$ the mass concentration of nano-PM was similar for both fuels ( $320 \mathrm{mg} / \mathrm{m}^{3}$ for diesel oil and $280 \mathrm{mg} / \mathrm{m}^{3}$ for RME) and it occurred for similar particle sizes, i.e. between approximately 0.1 and $1 \mu \mathrm{m}$. The nano-PM numeric amount was smaller for FAME (RME) than for the diesel fuel, but the differences are not as significant as in engine idling. The highest number concentration occurs for both fuels within the same range of particle dimensions, i.e. for $D p$ between 0.01 and $0.1 \mu \mathrm{m}$.

The situation is different with high engine load $(2000 \mathrm{rpm}, 250 \mathrm{Nm})$. In this case, both the mass concentration and number concentration of nano-PM are smaller for the bio-fuel (RME) than for the standard hydrocarbon fuel. The maximum mass concentration as well as the maximum number concentration occurred for both fuels within a similar range of particle sizes. Naturally, the high mass concentrations occur for bigger particles (approx. $1 \mu \mathrm{m}$ ) while the maximum number concentrations occur for significantly smaller particles (approx. $0.01 \mu \mathrm{m}$ ).

This research allows us to propose that in this case, from the point of view of PM mass and number concentration, for the FAME (RME) fuel, the most unfavourable is engine idling. In this situation, the injection pressure and temperature inside the engine cylinder, as well as the charging pressure, are small and the EGR rate is very high. At higher rotational speeds and engine loads, the PM number and mass concentration could be even smaller than for a diesel-fuelled engine. This may have a connection with the oxygen included in the RME particle, which at high temperatures can be utilised in the combustion process. Furthermore, the negative differences in the injection process and RME spraying are reduced in comparison with diesel fuel.

Such measurements are important not only in their utilitarian meaning (e.g. in choosing a suitable filter for particulates) but also in the cognitive sense when determining the influence of engine construction parameters and/or controlling parameters (or fuel composition) on the number and mass of particulates in the exhaust gases of a compression-ignition engine. In our own research (not included in this paper), we found substantial differences in the PM mass and number distribution between the exhaust gases of an engine fuelled by standard diesel fuel and the engine fuelled by RME (FAME).

\section{Final Findings}

The most important findings from this research data are as follows:

1. Engine load has an obvious influence on the number and mass concentrations of particles; nevertheless, it does not substantially change the (quantitative) distribution of these concentrations considered as a function of PM substitute diameters.

2. The highest mass concentration of particles in the engine exhaust gases was observed for particles between a range of 0.1 and $10 \mu \mathrm{m}$, and thus for relatively large particles.

3. The highest (quantity) number concentration of particles in the engine exhaust gases occurred for PM sizes between 0.01 and $0.1 \mu \mathrm{m}$, and thus for solid particles of at least an order of magnitude smaller than the mass concentration.

4. The biggest the negative differences in the mass concentration occur in the exhaust gases of the RME fuelled engine (in comparison with diesel fuel) at engine idling when the smallest injection pressure and temperature inside the engine cylinder exist and the oxygen availability is also the lowest (because of the small charging pressure and high EGR rate).

5. At high engine loads, the PM mass and number concentration may be lower for the RMEfuelled engine than for the engine fuelled with standard diesel fuel. 


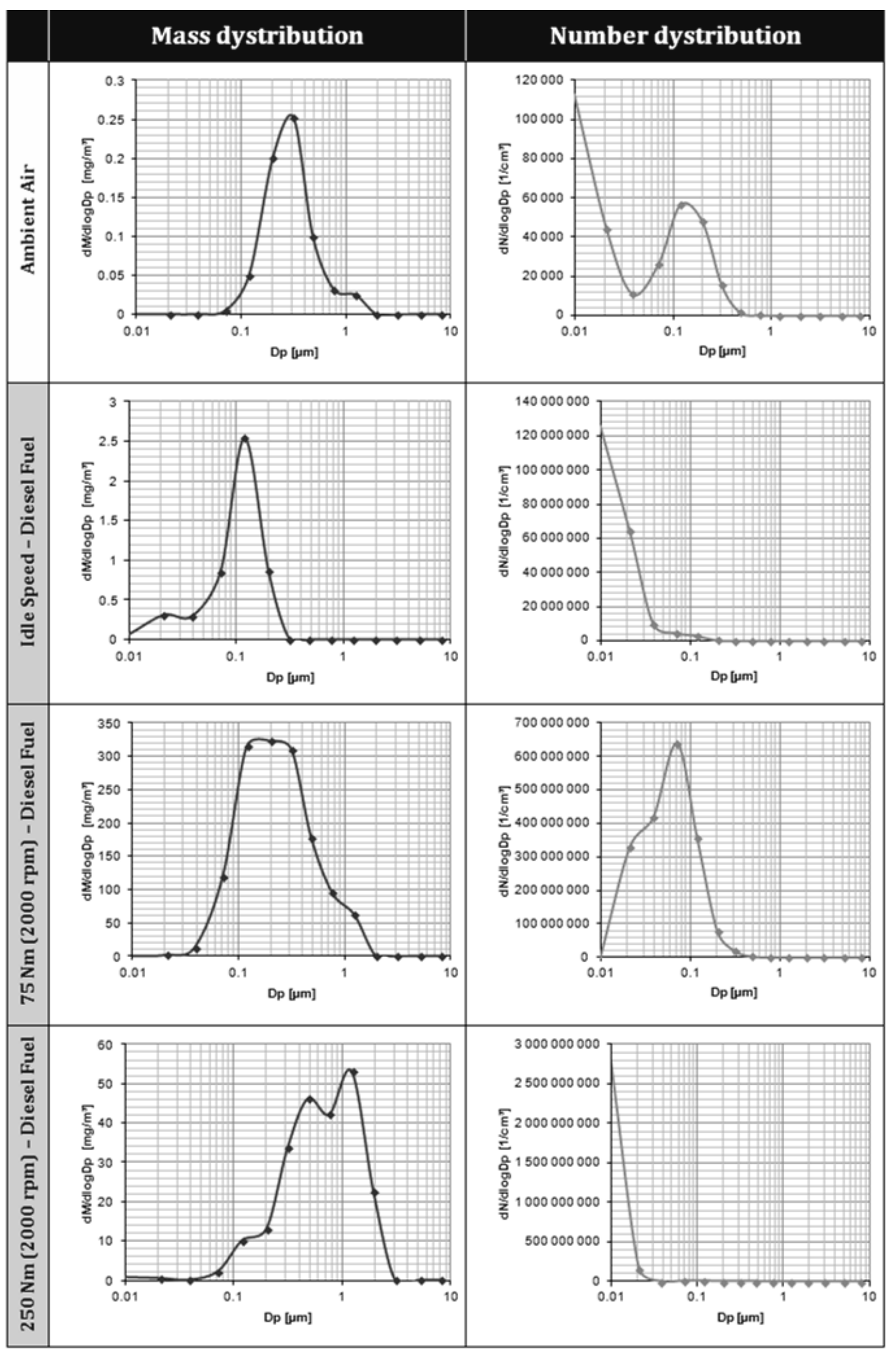

Fig. 6. Influence of the 1.9 TDI VW engine load on the PM mass and number concentration (as a function of particle diameters) in the exhaust gases of an engine fuelled by diesel fuel 


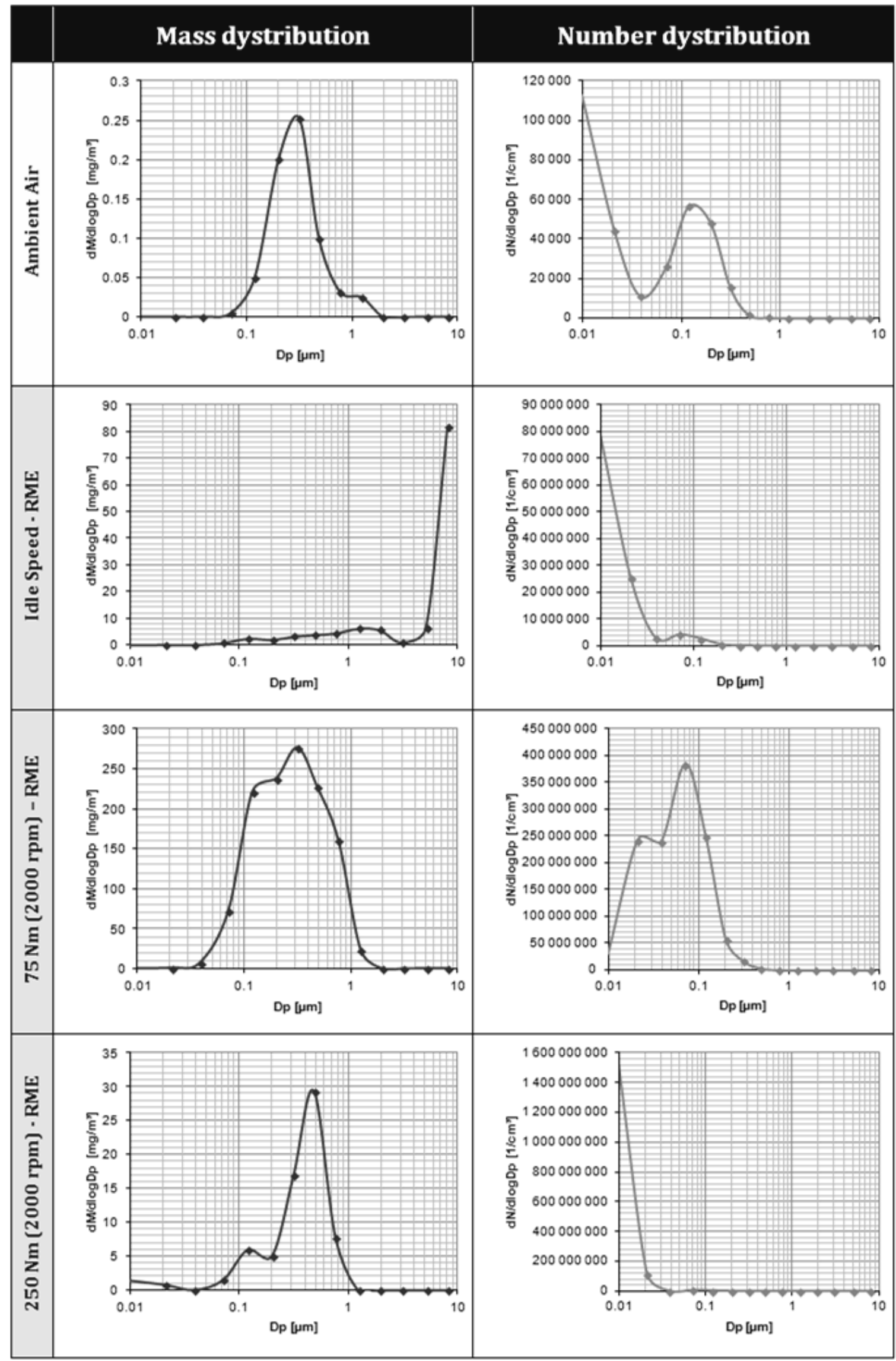

Fig. 7. Influence of the 1.9 TDI VW engine load on the PM mass and number concentration (as a function of particle diameters) in the exhaust gases of an engine fuelled by RME (FAME) 


\section{Acknowledgement}

This article is a result of the research covered by the agreement M-4/84/2013/DS.

\section{References}

[1] RIC Engines - Exhaust emission measurement, Part 1. Test bed measurement of gaseous and particulate exhaust emissions from RIC Engines, ISO, CD 8178 - 1, 1992.

[2] Emission of diesel engines, U.N. Economic Commission for Europe ECE), Regulation 49.

[3] US Environmental Protection Agency, Mobile Source Air Toxic, Proceedings 2010.

[4] ELPI+. Materiały firmy Dekati, 2012.

[5] Andrews, G. E., Clarke, A. G., Rojas, N. Y., Sale, T., Gregory, D., The Conversion of Particle Number Size Distribution to Mass Distribution, SAE 2001-01-1946.

[6] Cisek, J., Metodyka pomiaru koncentracji ilościowej nanocząstek emitowanych przez silniki spalinowe, Journal of KONES, 2002. 